\title{
Pragmatic Development of Chinese EFL Learners-A Study on FL Suggestions
}

\author{
Tongqing $\mathrm{Gu}^{1}$ \\ ${ }^{1}$ School of Foreign Languages, China West Normal University, Sichuan, China \\ Correspondence: School of Foreign Languages, China West Normal University, No. 1 Shi Da Road, Nanchong \\ 637009, Sichuan, China. Tel: 86-817-289-3129. E-mail: gutongqing820@gmail.com
}

Received: December 9, 2013 Accepted: January 21, 2014 Online Published: March 6, 2014

doi:10.5539/elt.v7n4p147 URL: http://dx.doi.org/10.5539/elt.v7n4p147

The research is financed by the Department of Education of Sichuan Province (Project No. 10SA023).

\begin{abstract}
While the number of studies on the pragmatic development of nonnative English speakers has been increasing, surprisingly little research has been conducted on the development of the ability of foreign language learners to perform the suggestion speech act, with even less taking Chinese EFL learners as the target group. The present study examines the development of Chinese EFL learners' pragmatic competence by investigating their performance of the suggestion speech act over time. Three sub-corpora representing three different periods of Chinese EFL learners' performance were selected from the SECCL (Spoken English Corpus of Chinese Learners) to discover the changes in the use of linguistic formulae as well as suggestion strategies by Chinese EFL learners. Their performance was then compared with that of native English speakers to find out whether there was evidence of improvement across the years. The results show that (1) changes were taking place in the use of linguistic formulae and suggestion strategies by Chinese learners from 1997 to 2003, with greater changes taking place from the year 2000 to 2003, and (2) there was evidence of increasing similarity between Chinese learners' performance of the suggestion speech acts and that of native English speakers. It can thus be concluded that Chinese learners' pragmatic ability in English improved to some extent over the years of the study.
\end{abstract}

Keywords: speech act, pragmatic development, suggestion, corpus, pragmatic competence

\section{Introduction}

The suggestion speech act- "an utterance that the speaker intends the hearer to perceive as a directive to do something that will be to the hearer's benefit" (Banerjee \& Carrell, 1988, p. 319), has been studied by different researchers in the past decades. According to Martínez-Flor (2005), studies of the suggestion speech act fall into two major categories: cross-cultural pragmatic studies and interlanguage pragmatic studies (ILP) - the study of “nonnative speakers' use and acquisition of L2 pragmatic knowledge" (Kasper \& Rose, 1999, p. 81). Compared with cross-cultural pragmatic studies of the suggestion speech act, however, there are only a few studies in the field of ILP (Bardovi-Harlig \& Hartford, 1990, 1993; Koike, 1994, 1996; Alcón, 2001; Matsumura, 2001, 2003), with even fewer dealing with the development of foreign language learners' pragmatic ability to perform the speech act of suggestion. Because the ability to perform speech acts appropriately is an indication of foreign/second language learners' pragmatic competence, which, in turn, constitutes a part of their "communicative comptetence" (Hymes, 1972), it is imperative to study how foreign/second language learners develop their ability to perform speech acts in the target language.

In the context of China, English is a foreign language learnt at all levels in Chinese schools. Since the mid-1990s, China has been carrying out reforms in foreign language education; many innovations have thus been made in English teaching and learning in China. With these changes, a question to be answered is whether Chinese EFL learners' pragmatic competence has improved accordingly. To answer this question, the present study, based on corpus data, examines the changes that have taken place in Chinese EFL learners' performance of the suggestion speech act in the past decade. Three sub-corpora representing three different periods of Chinese learners' performance were selected from the SECCL to analyze the changes in their choice of linguistic structures as well as suggestion strategies. The changes were then examined against the performance of the suggestion speech act 
by native English speakers to find out whether there were signs of improvements. It is hoped that the findings from this study will strengthen this aspect of English language teaching and learning in China.

\section{Studies on the Development of the Suggestion Speech Act}

The suggestion speech act has received less attention in comparison to the speech act of requesting, which has been extensively investigated (Schmidt et al., 1996). And there is little research on the pragmatic development of EFL learners' ability to perform the suggestion speech act. In relation to the present study, the literature to be reviewed in this section is confined to the developmental/ longitudinal studies on the suggestion speech act.

Bardovi-Harlig and Hartford (1993) conducted the first developmental study to address suggestions. On the basis of their previous study (1990), Bardovi-Harlig and Hartford (1993) carried out a longitudinal study to examine the change over the course of a semester in the students' ability to develop their pragmatic competence within the framework of status congruence. The participants consisted of 16 graduate students (6 NSs and 10 NNSs of English) and 7 native English-speaking faculty members. Both groups of subjects were taped in 35 advising sessions over the course of a semester. It was found that the non-native English-speaking students' pragmatic competence was improved over time. However, they did not show a better ability to employ appropriate linguistic forms of the suggesting speech act owing to the lack of appropriate input regarding suggestion formulae.

Matsumura (2001) carried out a longitudinal study comparing the development of 97 university-level Japanese exchange students' pragmatic competence with that of 102 peers in Japan who did not stay a year abroad. The research focused on the degree of change that took place over time in the perception of social status in advice acts. The data were collected by means of a multiple-choice questionnaire (MCQ) (with 12 scenarios and four response choices for each scenario), which was administered four times throughout the academic year. The results showed that the exchange students started lower in pragmatic performance than their peers but then outperformed them, indicating that living and studying in a target speech community was effective in developing pragmatic competence.

In another longitudinal study, Matsumura (2003) examined the effect of the level of proficiency and amount of exposure on the pragmatic development of 137 university-level Japanese learners of English. A multiple-choice questionnaire was used to measure the participants' preference for a particular suggestion strategy when offering advice in various advice-giving situations repeated in one academic year. Their pragmatic development was measured on the basis of the degree of their approximation to native speech act behavior. The results showed that the amount of exposure was potentially of greater importance in the learners' pragmatic development than their level of proficiency although the amount of exposure was determined in part by levels of proficiency.

The review of the literature on the pragmatic development of the suggestion speech act reveals that very few studies, with the exceptions of those above, have dealt with the development of foreign/second language learners' pragmatic competence in target language suggestions, and Chinese learners are a relatively understudied speaker group. Therefore, the present study offers a contribution to the body of research on acquisitional pragmatics through its investigation of the development of Chinese learners' pragmatic competence-specifically in their performance of the suggestion speech act over time.

\section{Methodology}

\subsection{Research Questions}

As noted above, the aim of the present study is to investigate the changes over time in Chinese EFL learners' performance of the suggestion speech act, through which evidence of their pragmatic development can be detected. Specifically, the study posed the following three research questions:

1) What is the overall picture of Chinese EFL learners' performance of the suggestion speech act?

2) What are the changes over time in the linguistic formulae of the suggestion speech act made by the Chinese EFL learners?

3) What are the changes over time in the use of suggestion strategies by the Chinese EFL learners?

\subsection{Materials}

The materials used in this study were three sub-corpora of the SECCL, which was constructed on the basis of the spoken English data of university sophomores in the National Spoken English Test for English Majors (Band 4) from 1996 to 2008 in China. The test is comprised of three tasks: Task One, the retelling of a story for three minutes; Task Two, a three-minute monologue based on a given topic; and Task Three, a four-minute role play between two test-takers. The test-takers' performances were audio-recorded in language labs, and the recordings 
were then transcribed by researchers. After several rounds of careful proofreading, the transcriptions were annotated to construct the corpus.

The data used in this study were the transcriptions of the third task (role playing) selected from the years 1997, 2000, and 2003 because the topics for the role play were the same - making suggestions in these three years, and there were equal intervals between the years so that changes could be examined across time. (Detailed information concerning the topics in these years can be found in Appendix A.) The extracted corpus consists of a total of 222 files, containing 129,664 word tokens, which formed, according to the time, three sub-corpora. More information of the extracted data of each year is shown in Table 1.

Table 1. Information of extracted corpus data of years 1997, 2000, \& 2003

\begin{tabular}{lccc}
\hline & Sub-corpus One (1997) & Sub-corpus Two (2000) & Sub-corpus Three (2003) \\
\hline Files & 74 & 74 & 74 \\
Word types & 2149 & 2783 & 2009 \\
Word tokens & 41070 & 48109 & 40485 \\
\hline
\end{tabular}

The reference corpus used in this study was the online MICASE (Michigan Corpus of Academic Spoken English), a spoken language corpus of approximately 1.8 million words focusing on contemporary university speech within the microcosm of the University of Michigan. The data used in this study were limited to the following features so as to be compatible with the spoken data of Chinese EFL learners:

Table 2. Features used in the corpus search in MICASE

\begin{tabular}{lccc}
\hline Speech event type & Participant level & Native speakers status & Interactivity rating \\
\hline Study group & Undergraduate & Native speakers, Amer E & Highly interactive \\
Discussion section & Graduate & Native speakers, Other E & Mostly interactive \\
\hline
\end{tabular}

\subsection{The Research Instrument}

Corpus concordancer, AntConc3.2.2, a powerful software package containing several analytical and statistic tools was used. The package includes seven tools, namely Concordance, Concordance Plot, File View, Clusters, Collocates, Word List, and Keyword List. This study mainly used the Concordance tool in order to retrieve a specified search word or structure in all the extracted text files. Access was also available to information about the collocation and context of the search word or structure, showing where it comes in each file.

\subsection{Data Collection and Data Analysis}

In order to discover the linguistic features of suggestions made by Chinese learners of English, we formulated a list of linguistic structures for making suggestions based on Jiang (2006), a pilot study of Chinese EFL learners' performance of suggestions in English, a careful analysis of their textbooks to locate the linguistic forms used for suggesting and a pilot search in the corpus. The linguistic forms were grouped into five categories based on their grammatical features. (A list of these structures used for concordance search is in Appendix B.)

The classification of suggestion strategies in this study, with reference to Blum-Kulka et al. (1989), was mainly based on Martínez-Flor (2005). Two levels of directness were distinguished in the present study, namely direct strategies and conventionally indirect strategies, depending on their directness. Direct suggestions are those whose illocutionary force is indicated in the utterance by grammatical and lexical means such as performative verbs-suggest/advise/recommend/propose - and their corresponding nouns, or imperative sentences. Conventionally indirect suggestions express the illocutionary force by fixed linguistic conventions established in English, including Wh-questions-How about..., What about...etc., modals-(You) can..., (You) may..., (You) should...etc., and conditionals If I were you..., If you... (Li, 2010) (The coding scheme of the suggestion strategies can be found in Appendix C).

AntConc 3.2.2 was used to search each structure in the three extracted corpora to determine the individual occurrences of the linguistic structures in the three separate years. Those occurrences where the structure was used in the corpus for functions other than suggestions were manually eliminated. Then the frequency of linguistic formulae and suggestion strategies employed by Chinese EFL learners in making suggestions in the 
three years was calculated and compared to investigate the changes taking place in the years. These changes were then compared to the performance of native English speakers to discover if there were signs of improvement in the Chinese learners' pragmatic competence.

\section{Results and Discussion}

This section reports and discusses the results of the present study in relation to the research questions. The occurrences and frequency of the linguistic formulae and the suggestion strategies from the three sub-corpora were presented and compared. Chi-square tests were conducted to check whether there were significant changes across the years.

\subsection{The Overall Picture of Chinese EFL Learners' Performance of the Suggestion Speech Act}

To answer the first research question, the occurrences and frequency of the linguistic structures and suggestion strategies employed by Chinese EFL learners in making suggestions in the three sub-corpora (representing three years) are presented in Table 3 and Table 4.

Table 3. Occurrences and frequency of linguistic formulae over three years

\begin{tabular}{|c|c|c|c|c|c|c|}
\hline \multirow[b]{2}{*}{ Structures } & \multicolumn{2}{|c|}{1997} & \multicolumn{2}{|c|}{2000} & \multicolumn{2}{|c|}{2003} \\
\hline & Occurrence & Frequency & Occurrence & Frequency & Occurrence & Frequency \\
\hline Let's & 6 & 1.46 & 0 & 0 & 18 & 4.45 \\
\hline Performatives & 12 & 2.92 & 11 & 2.29 & 23 & 5.68 \\
\hline I suggest/I * suggest & 8 & 1.95 & 4 & 0.83 & 10 & 2.47 \\
\hline My suggestion(s) & 2 & 0.49 & 0 & 0 & 3 & 0.74 \\
\hline I propose/I * propose & 0 & & 0 & & 0 & \\
\hline I recommend & 0 & & 0 & & 0 & \\
\hline I advise/I * advise & 2 & 0.49 & 2 & 0.42 & 3 & 0.74 \\
\hline My advice & 0 & 0 & 5 & 1.04 & 7 & 1.73 \\
\hline Modals \& semi-modals & 498 & 121.26 & 636 & 132.2 & 321 & 79.29 \\
\hline (You) can & 251 & 61.1 & 289 & 60.07 & 210 & 51.87 \\
\hline (You) could & 4 & 0.97 & 6 & 1.25 & 4 & 0.99 \\
\hline (You) may & 8 & 1.95 & 16 & 3.33 & 13 & 3.21 \\
\hline (You) might & 0 & & 0 & & 0 & \\
\hline (You) should & 146 & 35.55 & 185 & 38.48 & 54 & 13.34 \\
\hline (You) must & 63 & 15.34 & 97 & 20.16 & 9 & 2.22 \\
\hline (You) need & 4 & 0.97 & 2 & 0.42 & 3 & 0.74 \\
\hline (You) have to & 14 & 3.41 & 28 & 5.82 & 10 & 2.47 \\
\hline (You)'d better & 8 & 1.95 & 13 & 2.70 & 18 & 4.45 \\
\hline Wh-questions & 17 & 4.14 & 22 & 4.57 & 33 & 8.15 \\
\hline How about & 5 & 1.22 & 11 & 2.29 & 16 & 3.95 \\
\hline What about & 2 & 0.49 & 8 & 1.66 & 14 & 3.46 \\
\hline Why not & 8 & 1.95 & 2 & 0.42 & 2 & 0.49 \\
\hline Why don’t you & 2 & 0.49 & 1 & 0.21 & 1 & 0.25 \\
\hline Conditionals & 108 & 26.3 & 88 & 18.29 & 183 & 45.2 \\
\hline If I were you & 0 & & 0 & & 11 & 2.72 \\
\hline If you & 108 & 26.3 & 88 & 18.29 & 172 & 42.48 \\
\hline
\end{tabular}

Note: Occurrence refers to total occurrences in the corpus and frequency refers to the number of occurrences per 10000 words. 
As shown in Table 3, Chinese EFL lerarners made use of all the five categories of linguistic structures to make suggestions. In the three sub-corpora, the most frequently used linguistic formulae were modals, followed by conditionals. Among the modal verbs retrieved from the sub-corpora to make suggestions, the most frequently used modal verb was (you) can signifying a possibility or the speaker's ability to conduct an act. The second most frequently used was the obligation modals should and must. Other less imposing modals like may, and could were rarely used, with might being the one that was not used at all. While you can was found to be the most frequently used linguistic structure in making suggestions by Rintell (1981), the use of must and should to make suggestions to interlocutors of equal status may be inappropriate and impolite. Further, as observed by Liang (2008), Chinese EFL learners tend to overuse those modal verbs that appear earlier in textbooks, and to underuse those modal verbs characterized by interpersonal functions as well as those often used for unreal conditions. Consequently, Chinese EFL learners exhibit an inability to choose the appropriate modal verbs to fulfil the desired speech functions.

As shown in Table 3, the conditionals were also frequently used in comparison to other linguistic forms, but the use of the conditional structure if you far exceeded the use of if I were you. Chinese learners' avoidance of using if I were you can be possibly attributed to their insufficient linguistic competence because this structure is more complicated than if you, and it involves the use of subjunctive mood which is studied later in grammar.

Table 3 also shows that the less frequently used linguistic means for making suggestions were wh-questions, performatives and the Let's structure. The first category, Let's, was sparsely used in three sub-corpora (6 vs. 0 vs. 18). Let's is described as "an inclusive imperative," including both the speaker and the addressee (Celce-Murcia et al., 1999, p. 233). Compared with bare imperatives, the use of Let's... makes the suggestion less authoritative and more collaborative. The Chinese learners, however, may have learned this structure solely as a joint action taken by both the speaker and hearer rather than as a linguistic formula to make suggestions, and thus did not use this structure as frequently as other linguistic formulae.

As for performatives, including performative verbs and their corresponding nouns, the occurrences and frequency were quite low. Performative verbs like propose, and recommend were not used by Chinese learners of English at all. These two verbs and their corresponding nouns, unlike suggest and advise, are not typically presented in textbooks as linguistic forms for making suggestions; thus Chinese learners are less familiar with them. In terms of Wh-questions, the occurrences were also low. In comparison, how about and why not were more frequently used than what about and why don't you. In English textbooks published in China, Wh-questions have been considered one of the most typical forms for making suggestions. The negative question form why don't you, according to Banerjee and Carrell (1988, p. 342), "is less polite in that it presupposes that the hearer knows that he or she should perform the desired action and asks for a reason that the hearer has not." Chinese learners seemed to understand the implications carried by this structure and intentionally avoid using it, which explains the low frequency of their use.

Table 4. Occurrences and frequency of suggestion strategies over three years

\begin{tabular}{lcccccc}
\hline \multirow{2}{*}{ Year } & \multicolumn{2}{c}{1997} & \multicolumn{2}{c}{2000} & \multicolumn{2}{c}{2003} \\
\cline { 2 - 7 } Strategies & Occurrence & Frequency & Occurrence & Frequency & Occurrence & Frequency \\
\hline Direct strategies & 18 & 4.38 & 11 & 2.29 & 41 & 10.13 \\
Performatives & 12 & 2.92 & 11 & 2.29 & 23 & 5.68 \\
Imperatives & 6 & 1.46 & 0 & & 18 & 4.45 \\
\hline Indirect strategies & 623 & 151.69 & 746 & 155.06 & 537 & 132.64 \\
Modals & 498 & 121.26 & 636 & 132.20 & 321 & 79.29 \\
Wh-questions & 17 & 4.14 & 22 & 4.57 & 33 & 8.15 \\
Conditionals & 108 & 26.30 & 88 & 18.29 & 183 & 45.2 \\
\hline
\end{tabular}

With regard to suggestion strategies, as shown in Table 4, indirect suggestion strategies were more frequently used than direct strategies over the years. As the spoken data used in this study were the interactions between university students who were peers talking about events on campus, such factors as power and distance were not of great importance. Considering the nature of the interaction and the role relationships between the interlocutors, it is easy to understand the choice of direct suggestion strategies by Chinese learners of English. As for the more 
frequent use of indirect strategies, this can be explained by Li's (2010, p. 611) observation that Chinese learners "seemed to be more comfortable in those overt and conventionalized choices, avoiding the possibility of being misinterpreted or overlooked." Since English is a foreign language in China, learners are rarely exposed to the target language environment and the language input is far from adequate, leading to an over reliance on the conventionalized structures presented in their textbooks.

4.2 Changes in Linguistic Formulae for the Suggestion Speech Act over Time

Table 5. Chi-square tests of Chinese learners' use of linguistic formulae between years

\begin{tabular}{lcccccc}
\hline \multicolumn{1}{c}{ Chi-square tests } & \multicolumn{2}{c}{1997 vs. 2000} & \multicolumn{2}{c}{1997 vs. 2003} & \multicolumn{2}{c}{2000 vs. 2003} \\
Structures & $\mathrm{X}^{2}$ & Sig. & $\mathrm{X}^{2}$ & Sig. & $\mathrm{X}^{2}$ & Sig. \\
\hline Let's & 9.3044 & 0.002 & 6.4523 & 0.011 & 28.1927 & 0.000 \\
\hline Performatives & 0.3454 & 0.556 & 3.6760 & 0.055 & 11.9760 & 0.000 \\
I suggest/I * suggest & 2.0669 & 0.150 & 0.2523 & 0.615 & 15.6626 & 0.000 \\
\hline Modals\& semi-modals & 2.0920 & 0.148 & 36.0590 & 0.000 & 58.4058 & 0.000 \\
You should & 0.5050 & 0.477 & 42.6457 & 0.000 & 55.0907 & 0.000 \\
You must & 2.9018 & 0.088 & 44.7872 & 0.000 & 70.9466 & 0.000 \\
\hline Wh-questions & 0.0955 & 0.757 & 5.4432 & 0.019 & 4.5216 & 0.033 \\
\hline Conditionals & 6.4331 & 0.011 & 20.6407 & 0.000 & 52.4260 & 0.000 \\
If I were you & 0.0000 & 1.000 & 15.4076 & 0.000 & 17.2289 & 0.000 \\
If you & 6.4331 & 0.011 & 15.6912 & 0.000 & 44.0572 & 0.000 \\
\hline
\end{tabular}

Table 5 displays the results of chi-square tests to examine changes in the use of these linguistic structures over the three years. As shown in Table 5, there was not much change from 1997 to 2000 in the use of the five categories of linguistic forms. The chi-square tests indicated that there was no significant difference between the frequency of their use in making suggestions ( $p>.001)$. From 1997 to 2003, however, the chi-square tests indicated that there were significant changes in the use of modals (\& semi-modals) $\left(\mathrm{X}^{2}=36.0590, p=.000<.001\right)$ and conditionals $\left(\mathrm{X}^{2}=20.6407, p=.000<.001\right)$. In terms of modals, the chi-square test indicated that there was a significant difference between the year 1997 and 2003 in the use of should $\left(\mathrm{X}^{2}=42.6457, p=.000<.001\right)$, and must $\left(\mathrm{X}^{2}=44.7872, p=.000<.001\right)$ between the two years. Another change across the two years occurred in the use of conditionals; the chi-square test indicated that the difference over the two years was significant $\left(\mathrm{X}^{2}=\right.$ $20.6407, p=.000<.001)$. Both the use of if I were you $\left(\mathrm{X}^{2}=15.4076, p=.000<.001\right)$ and if you $\left(\mathrm{X}^{2}=15.6912, p\right.$ $=.000<.001)$ were significantly different over the years.

Although signs of changes could be seen between the year 1997 and 2003, more changes were found in the period between the year 2000 and 2003. According to Table 5, there were significant changes in the use of all the linguistic structures except wh-questions. The greatest change occurred in the use of modals $\left(\mathrm{X}^{2}=58.4058, p\right.$ $=.000<.001)$, particularly in the use of the two obligation modal verbs must $\left(\mathrm{X}^{2}=70.9466, p=.000<.001\right)$ and should $\left(\mathrm{X}^{2}=55.0907, p=.000<.001\right)$. There were also significant differences between the use of Let's $\left(\mathrm{X}^{2}=\right.$ $28.1927, p=.000<.001)$, the performative verb, suggest $\left(\mathrm{X}^{2}=15.6626, \mathrm{p}=.000<.001\right)$ and the conditional structures if you $\left(\mathrm{X}^{2}=44.0572, p=.000<.001\right)$ and if I were you $\left(\mathrm{X}^{2}=17.2289, \mathrm{p}=.000<.001\right)$ between the two years. The comparison across the years suggests that there were changes taking place in the use of linguistic formulae for making suggestions from 1997 to 2003, with greater changes taking place between the year 2000 and 2003.

To examine whether the changes in the use of linguistic formulae was evidence of improvement in Chinese learners' pragmatic competence, we compared the frequency of these structures used by Chinese learners over the years with the frequency of their use by native English speakers. Such a comparison enabled us to see ways in which the Chinese learners' use of the structures approaches or deviates from that of native English speakers. 


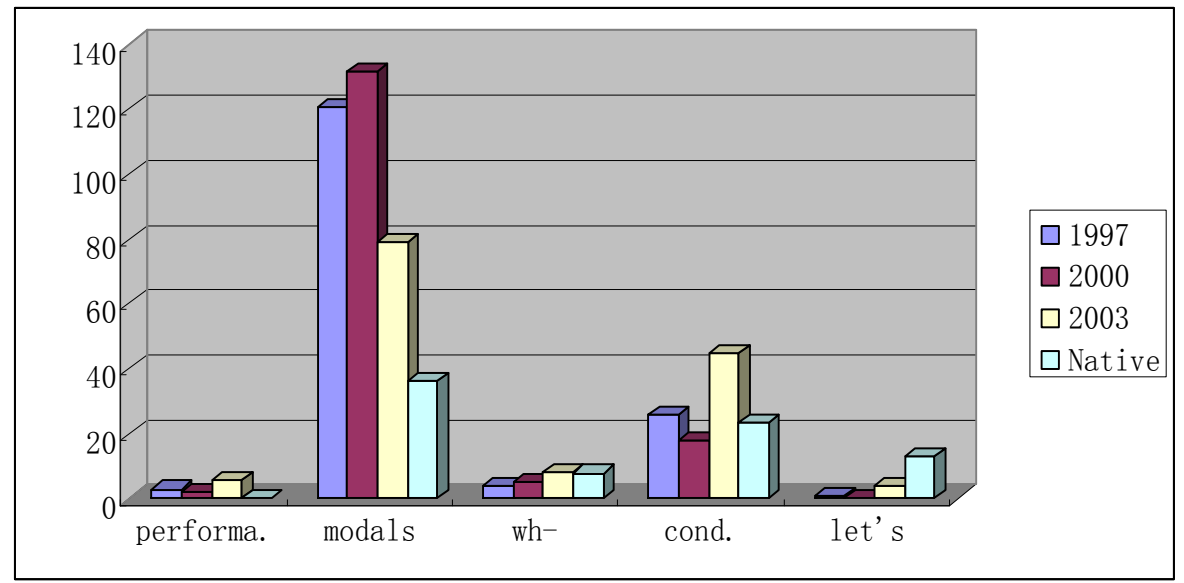

Figure 1. Comparison between Chinese learners and native English speakers in linguistic formulae

Figure 1 demonstrates clearly the differences and similarities between Chinese EFL learners and native English speakers in their use of the five categories of linguistic structures in making suggestions. As shown in Figure 1, Chinese learners and native English speakers were similar in the general pattern of their use of the five linguistic structures. As for the differences in the use of a specific linguistic structure, the use of modals decreased dramatically from 2000 to 2003 which approached the frequency of their use by native English speakers; similarly, the use of wh-questions increased from 1997 to 2003, and the frequency of their use was almost the same as that of the native English speakers in the sub-corpus of 2003. The use of the let's structure increased across the years, gradually approaching the use of native speakers. However, there were also marked differences between Chinese learners and native English speakers in the use of performatives and conditionals, both of which were on the increase in 2003, which seemed to deviate from the native speaker norms. These differences show that these are areas that need improvement in Chinese learners' use. Overall, however, the results point to the fact that there were signs of progress in the use of the linguistic structures for making suggestions by Chinese EFL learners. Thus Chinese learners' pragmatic ability to employ the proper suggestion formulae improved, to some extent, across the years.

\subsection{Changes in Suggestion Strategies over Time by Chinese Learners}

Table 6. Chi-square tests of Chinese learners' suggestion strategies between years

\begin{tabular}{lcccccc}
\hline \multirow{2}{*}{ Chi-square tests } & \multicolumn{2}{c}{1997 vs. 2000} & \multicolumn{2}{c}{1997 vs. 2003} & \multicolumn{2}{c}{2000 vs.2003 } \\
\cline { 2 - 7 } Strategies & $\mathrm{X}^{2}$ & Sig. & $\mathrm{X}^{2}$ & Sig. & $\mathrm{X}^{2}$ & Sig. \\
\hline Direct strategies & 2.9950 & 0.083 & 9.5412 & 0.002 & 23.9872 & 0.000 \\
Performatives & 0.3454 & 0.556 & 3.6760 & 0.055 & 6.6511 & 0.009 \\
Imperatives (Let's) & 9.3044 & 0.002 & 6.4523 & 0.011 & 28.1927 & 0.000 \\
\hline Indirect strategies & 0.1642 & 0.685 & 5.2076 & 0.022 & 7.6744 & 0.005 \\
Modals & 2.0920 & 0.148 & 36.0590 & 0.000 & 58.4058 & 0.000 \\
Wh-questions & 0.0955 & 0.757 & 5.4432 & 0.019 & 4.5216 & 0.033 \\
Conditionals & 6.4331 & 0.011 & 20.6407 & 0.000 & 52.4260 & 0.000 \\
\hline
\end{tabular}

As shown in Table 6, there was no significant difference between the year 1997 and 2000 in Chinese learners' use of both direct and indirect suggestion strategies ( $>$ >.001). However, changes occurred from the year 1997 to 2003 in the use of indirect suggestion strategies. The chi-square tests indicated that there was a significant difference between the use of modals $\left(\mathrm{X}^{2}=36.0590, p=.000<.001\right)$ and conditionals $\left(\mathrm{X}^{2}=20.6407, p\right.$ $=.000<.001)$, although there was no significant difference on the whole. Greater changes occurred between the year 2000 and 2003 in the use of suggestion strategies. According to Table 6, there was a significant difference in the use of direct strategies between 2000 and $2003\left(\mathrm{X}^{2}=23.9872, p=.000<.001\right)$. However, there was no 
significant change in the use of indirect suggestion strategies across the years $\left(\mathrm{X}^{2}=7.6744, p=.005>.001\right)$. The chi-square test indicated there were significant differences between the year 2000 and 2003 in the use of modals $\left(\mathrm{X}^{2}=36.0590, \mathrm{p}=.000<.001\right)$ and conditionals $\left(\mathrm{X}^{2}=52.4260, \mathrm{p}=.000<.001\right)$. The comparison across the years suggests that there were changes in suggestion strategies over the years, with greater changes taking place between the year 2000 and 2003 .

To examine whether the changes were signs of improvement in Chinese learners' pragmatic competence, we compared the frequency of the suggestion strategies used by Chinese learners over the three years with that of the native English speakers to find out conformity to and deviation from the native speaker norms.

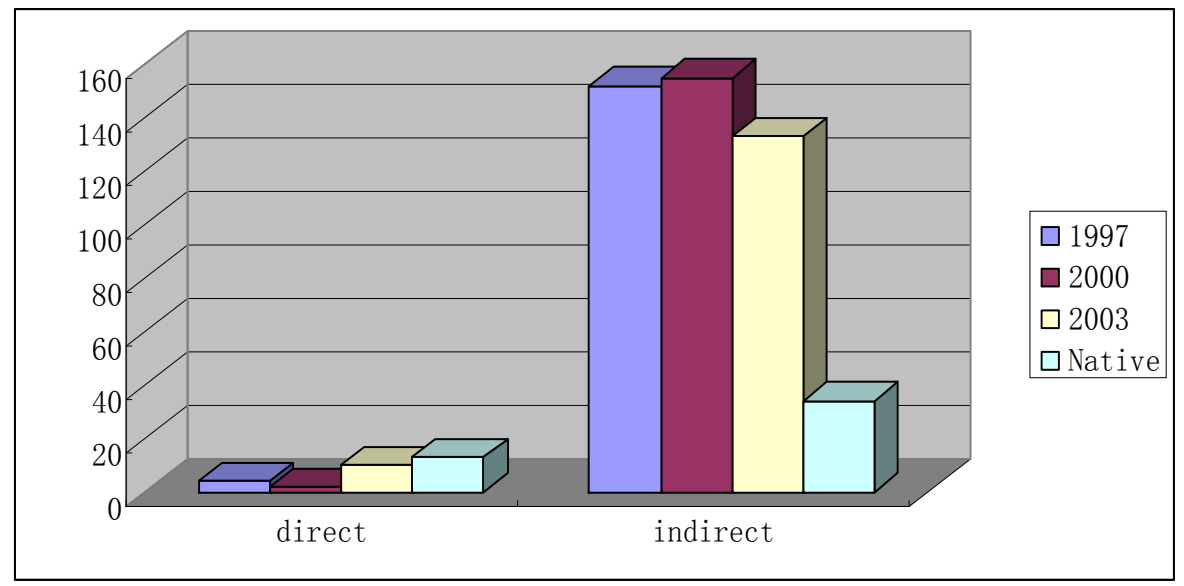

Figure 2. Comparison between Chinese learners and native English speakers in suggestion strategies

As shown in Figure 2, there were signs of improvement in the choice of suggestion strategies over the years. With regard to direct strategies, there was a gradual increase over the years in the choice of direct strategies by Chinese learners of English. In the year 2003, more direct strategies were used by Chinese learners, conforming to the use of this strategy by native English speakers. In terms of indirect suggestion strategies, although the Chinese learners used far more indirect suggestion strategies than native English speakers, there was a decrease in their use by Chinese learners from the year 2000 to 2003, marking a gradual approach to the native speaker norms. The results suggest that there were changes in the use of suggestion strategies by Chinese learners of English, and Chinese learners' pragmatic competence was on the road of gradual development with time passing by.

\section{Conclusion}

The present study examined the development of Chinese EFL learners' pragmatic competence through investigating their performance of the suggestion speech act over time. The results showed that changes took place in the use of linguistic formulae and suggestion strategies by Chinese learners for making suggestions from the year 1997 to 2003, with greater changes taking place from the year 2000 to 2003 . Through comparing the performance of the suggestion speech act of Chinese learners with that of native English speakers, we found that there was evidence of progress in both the use of linguistic structures and the employment of suggestion strategies by Chinese learners' to make suggestions. This finding points to the fact that Chinese learners' English pragmatic ability, has, to some extent, improved across the years, especially in more recent years.

This study adopted a cross-sectional design, which "looks at different learners at different moments in time and establishes development by comparing these successive states in different people" (Cook, 1993, p. 78), to investigate the pragmatic development of Chinese EFL learners. Future research could adopt a longitudinal approach which requires "the observation of the same participant(s) over an extended period" (Kasper \& Rose, 2002 , p. 73) so that the developmental patterns of learners can be observed more closely and causal relationships between pragmatic development and variables such as levels of proficiency, amount of exposure and ways of instruction can be established. In addition, more studies on other aspects of pragmatic development such as recognition and production of routine formulae as well as comprehension of implicature are needed to verify the developmental stages of pragmatic competence proposed by previous researchers (Ellis, 1992; Kasper \& Rose, 2002). 


\section{Acknowledgements}

I would like to thank my advisor Nancy Lee at EMU, and the anonymous reviewers, for their valuable comments on an earlier version of this article.

\section{References}

Banerjee, J., \& Carrell, P. (1988). Tuck in your shirt, you squid: Suggestion in ESL. Language Learning, 38, 313-347. http://dx.doi.org/10.1111/j.1467-1770.1988.tb00416.x

Bardovi-Harlig, K., \& Hartford, B. S. (1990). Congruence in native and nonnative conversations: Status balance in the academic advising session. Language Learning, 40, 467-501. http://dx.doi.org/10.1111/j.1467-1770.1990.tb00603.x

Bardovi-Harlig, K., \& Hartford, B. S. (1993). Learning the rules of academic talk: A longitudinal study of pragmatic development. Studies in Second Language Acquisition, 15, $279-304$. http://dx.doi.org/10.1017/S0272263100012122

Blum-Kulka, S., \& Kasper, H. J. (Eds.). (1989). Cross-cultural pragmatics: Requests and apologies. Ablex, NJ: Norwood.

Celce-Murcia, M., \& Larsen-Freeman, D. (1999). The grammar books: An ESL/EFL teacher's course. Boston, MA: Heinle and Heinle Publishers.

Cook, V. (1993). Linguistics and second language acquisition. New York, NY: St. Martins Press.

Ellis, R. (1992). Learning to communicate in the classroom: A study of two language learners' requests. Studies in Second Language Acquisition, 14, 1-23. http://dx.doi.org/10.1017/S0272263100010445

Hymes, D. H. (1972). On communicative competence. In J. B. Pride, \& J. Holmes (Eds.), Sociolinguistics: Selected readings (pp. 269-293). Harmondsworth: Penguin.

Jiang, X. Y. (2006). Suggestions: What should ESL students know? System, 34, 36-54. http://dx.doi.org/10.1016/j.system.2005.02.003

Kasper, G., \& Schmidt, R. (1996). Developmental issues in interlanguage pragmatics. Studies in Second Language Acquisition, 18, 149-169. http://dx.doi.org/10.1017/S0272263100014868

Kasper, G., \& Rose, K. R. (1999). Pragmatics and SLA. Annual Review of Applied Linguistics, 19, 81-104. http://dx.doi.org/10.1017/S0267190599190056

Kasper, G., \& Rose, K. R. (2002). Pragmatic development in a second language. Language Learning, 52(Suppl. 1), 1-339. http://dx.doi.org/10.1111/j.1467-1770.2002.tb00022.x

Koike, D. A. (1994). Negation in Spanish and English suggestions and requests: Mitigating effects? Journal of Pragmatics, 21, 513-526. http://dx.doi.org/10.1016/0378-2166(94)90027-2

Koike, D. A. (1996). Transfer of pragmatic competence and suggestions in Spanish foreign language learning. In S. M. Gass, \& J. Neu (Eds.), Speech acts across cultures (pp. 257-281). Berlin: Mouton de Gruyter.

Liang, M. C. (2008). A corpus-based study of modal sequences in Chinese tertiary EFL learners'written production. Foreign Language Teaching and Research, 40(1), 51-58.

Li, S. E. (2010). Making suggestions: A contrastive study of young Hong Kong and Australian students. Journal of Pragmatics, 42, 598-616. http://dx.doi.org/10.1016/j.pragma.2009.07.014

Martínez-Flor, A. (2005). A theoretical review of the speech act of suggesting: Towards a taxonomy for its use in FLT. Revista Alicantina de Estudios Ingleses, 18, 167-187.

Martínez-Flor, A., \& Yoshinori, J. F. (2005). The effects of instruction on learners' production of appropriate and accurate suggestions. System, 33, 463-480. http://dx.doi.org/10.1016/j.system.2005.06.007

Matsumura, S. (2001). Learning the rules for offering advice: A quantitative approach to second language socialization. Language Learning, 51, 635-679. http://dx.doi.org/10.1111/0023-8333.00170

Matsumura, S. (2003). Modelling the relationships among interlanguage pragmatic development, L2 proficiency, and exposure to L2. Applied Linguistics, 24, 465-491. http://dx.doi.org/10.1093/applin/24.4.465

Rintell, E. (1981). Sociolinguistic variation and pragmatic ability: A look at learners. International Journal of the Sociology of Language, 27, 11-34.

Rose, K. R., \& Kasper, G. (Eds.). (2001). Pragmatics in language teaching. Cambridge: Cambridge University 
Press. http://dx.doi.org/10.1017/CBO9781139524797

Schmidt, R. et al. (1996). Suggestions to buy: Television commercials from the U.S., Japan, China, and Korea. In S. M. Gass, \& J. Neu (Eds.), Speech acts across cultures (pp. 285-316). Berlin: Mouton de Gruyter.

Wen, Q. F., Wang, L. F., \& Liao, M. (2005). Spoken and written English corpus of Chinese learner (1.0). Beijing: Foreign Language Teaching and Research Press.

Wen, Q. F. et al. (2008). Spoken and written English corpus of Chinese learners (2.0). Beijing: Foreign Language Teaching and Research Press.

\section{Appendices}

\section{Appendix A}

National English Spoken Test (Band 4)

Task III Role-playing (1997)

Student A: Your department is going to have an English speech contest. You are eager to enter it but you have a lot of worries. So you come to your friend for advice. First of all, you and your friend are talking about the reasons why you are eager to take part in the contest and what is worrying you. Your friend is trying to help you. However, you don't think all his/her suggestions are helpful. You are trying to give him/her more explanation about your own situation.

Student B: Your department is going to have an English speech contest. Your friend wants to enter it and at the same time he/she has a lot of worries. Now he/she comes to you for advice. After hearing his/her problems attentively, you give him/her some suggestions by sharing your own experience with him/her. However, your friend doesn't think all your suggestions are helpful and he/she tries to give you more explanations about his/her situation. By having a better understanding of his/her situation, you are able to give him/her better suggestions.

Task III Role-playing (2000)

Student A: You are a freshman who has just enrolled in your university. You are wondering about what the university life would be though you have heard a lot of it. To be honest, you are a little bit lost and afraid of the coming university life. Now you meet a sophomore of your department and ask him/her for advice on how to make good use of time, how to study well and how to make friends in the university. Eventually, you become confident about your future again.

Student B: You are a sophomore at the university. A freshman of your department comes to you to ask for advice on how to become successful in the university. You share your experience of the university life with him/her. You try to tell him/her how to make good use of time, how to study well and how to make friends in the university. Eventually you make him/her confident about his/her future again.

Task III Role-playing (2003)

Student A: You will be traveling later this week and you are wondering about the advantages and safety of flying. Recent news reports of air crashes have made you nervous and you cannot decide if it is safe to travel by airplane. You turn to your friend for advice about whether you should go by air or by train. He/She tried to persuade you to take a flight by listing some advantages. Eventually, you refuse to accept his/her opinion and make your own decision.

Student B: One of your friends is taking a trip later this week and he/she is undecided about whether to travel by air or by train. Not knowing what to do, your friend comes to you for advice. You try to persuade your friend to take a flight in spite of reports of air crashes. Eventually, you fail to convince him/her and your friend buys a train ticket instead.

Appendix B

List of structures used for concordance search

1) Let's ...

2) Modals and semi-modals

You have to ...

You * have to ... (* means with one word in-between.)

You need to ...

You $*$ need to $\ldots$ 
You should ...

You shouldn't ...

You ought to ...

You must ...

You could ...

You might ...

You're supposed to ...

You'd/had better ...

3) Wh-questions

Why don't you ...?

Why not ...?

How about ...?

What about ...?

4) Conditionals

If I were ...

If you ...

5) Performatives

Suggest/Recommend/Advise/Propose

Suggestion/Recommendation/Advice/Proposal

Appendix C

The Coding Scheme for Suggestion Strategies

\begin{tabular}{|c|c|c|}
\hline Category & Sub-category & Example \\
\hline \multirow{4}{*}{ Direct } & Performative verbs & I suggest/ advise/ recommend/ propose you ... \\
\hline & Noun of suggestion & My suggestion/ proposal/ recommendation ... \\
\hline & \multirow{2}{*}{ Imperative sentences } & Please do.... \\
\hline & & Let's... \\
\hline \multirow{13}{*}{ Conventionally indirect } & \multirow{4}{*}{ Wh-questions } & Why don't you...? \\
\hline & & How about...? \\
\hline & & What about...? \\
\hline & & Have you thought about...? \\
\hline & \multirow{8}{*}{ Modals and semi-modals } & You can \\
\hline & & You could \\
\hline & & You may \\
\hline & & You might \\
\hline & & You need... \\
\hline & & You must... \\
\hline & & You should/ ought to \\
\hline & & You had better... \\
\hline & Conditionals & $\begin{array}{l}\text { If I were you, I would... } \\
\text { If you... }\end{array}$ \\
\hline
\end{tabular}

\section{Copyrights}

Copyright for this article is retained by the author(s), with first publication rights granted to the journal.

This is an open-access article distributed under the terms and conditions of the Creative Commons Attribution license (http://creativecommons.org/licenses/by/3.0/). 